

J. Environ. Sci. \& Natural Resources, 6(2): 139-147, 2013

ISSN 1999-7361

\title{
Stream Barb Influenced on Straight Channel Bed Configuration: A Numerical Simulation
}

\author{
S. A. A. Mamun Hossain ${ }^{1}$, A. K. M. Adham ${ }^{2}$ and M. J. Uddin ${ }^{3}$ \\ ${ }^{1}$ Department of Agricultural Engineering, Patuakhali Science and Technology University, \\ Dumki, Patuakhali-8602.Bangladesh. \\ ${ }^{2}$ Department of Irrigation and Water Management, Bangladesh Agricultural University, \\ Mymensingh-2202, Bangladesh \\ ${ }^{3}$ Department of Civil Engineering, Khulna University of Engineering \& Technology, Khulna- \\ 9203, Bangladesh.
}

\begin{abstract}
The focus of this study is to observe the influence of barb on channel bed configuration by using iRICNays2D, a multi-dimensional computational model for river flow and riverbed variation analysis solver package. The two-dimensional (2D) numerical simulation is represent the effects the pre-existing condition (i.e. before construction of barb) and in the presence of the barb installed on sidewall of the channel. The average flow depth, and discharge were used as $0.044 \mathrm{~m}$ and $0.028 \mathrm{~m}^{3} / \mathrm{s}$, respectively. The numerical simulation reproduced the features of barb with time at upward side and creates scour holes at the leeward side of the structure. The simulation results confirmed that the vicinity of the barb head achieved a substantial reduction in scour, increase stream-wise velocity and sediment deposition at near bank. Bars were formed along the bank-line at the upstream portion of the structures. On the other hand, at the downstream side near the barb head scour occurs due to hydraulic jump and turbulence flow mixing.
\end{abstract}

Keywords: Bars, Bed configuration, Numerical simulation, Stream barb, Turbulence flow

\section{Introduction}

The changes of river are interrelated not only with bank erosion but also with bed deformation. This is because of the relationship between water flow and sediment transport. Beside of bank erosion it is needed to study about the bed deformation for maintaining river ecosystems and landscape in the field for environmental engineering purpose. Stream barbs are relatively a new form of bank protection structure. It is defined as wide crested trapezoidalshaped structures that project out from the stream bank into the main channel flow to modify flow patterns and bed topography. Typically, constructed of large angular rock (riprap); barbs protrude into the flow at an angle upstream to the channel sidewall (bank) for the purpose of deflecting current away from the bank and minimizing the erosion potential (Ghodsian and Tehrani, 2001; Breusers and Raudkivi, 1991). Barbs are quite similar to spur dikes, groynes (groins), and submerged vanes; they have some distinct features as shown in Fig. 1. The most defining feature is the trapezoidal shape of the structure with inclined sides and a wide sloped crest, which allows the barb to behave as a partially submerged structure (weir) when flow is low and fully submerged when bankfull flow conditions are present. When pointed upstream the submerged weir section forces the water flowing over the structure into a hydraulic jump (Fox, 2002). The flow separation induced by the hydraulic jump promotes the formation of eddies and sediment deposition on the leeward side of the barb (Lloyd and Stansby, 1997). Generally barbs are used to protect banks for gentle (wide radius) meanders, or relatively straight banks. The primary function of barbs is to deflect the strong main flow away from critical zones towards the channel center and therefore, prevent erosion of banks (Hansen and Winter 1996). It also used on long reaches of relatively straight or gently curving banks that need protection. The approaches to protect stream banks from erosion during periods of high flows including various bio-technical type channel revetments (Schiechtl and Stern, 1997) and groin like structure including bend-way weirs (Davinroy, 1990, 1994) and barbs (USDA, 2001). While bend-way weirs and barbs are design primarily to protect unstable outside bank zones of channel bend from the bank-undermining and local erosion process associated with bend secondary currents. As well as providing bank protection, these structures promote vegetated stream banks, create resting pools and scour holes for fish habitat, and increase bio-diversity for aquatic species. Barbs have been used by the Natural Resources conservation Service (NRCS) of US department of agriculture, in Oregon for river and stream bank protection since the late 1980. The Washington State Department of Transportation (WSDOT) has employed barbs for bank protection along highways or river crossings and/or to improve aquatic conditions, especially in shallow gravel bed streams (Papanicolaou et al. 2004). 

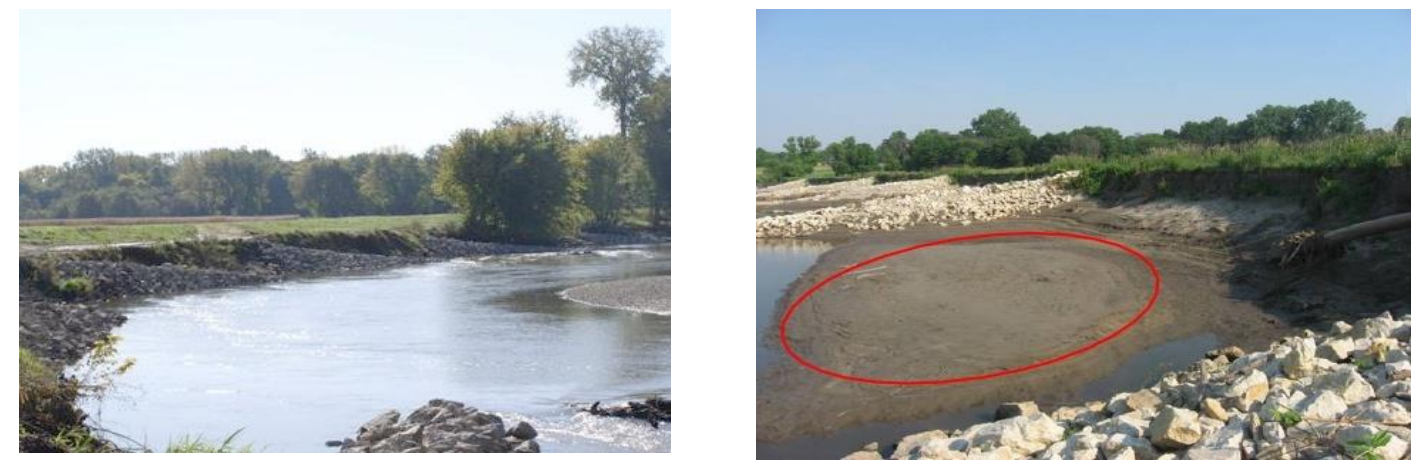

Fig. 1. Photographic view shows the series of stream barbs installed along the river bank during flow season (left-hand side) and low flow season (right-hand side). The red circle indicates sand bars formed after installation of barbs.

Study of channel bed configuration has become crucial for examination of the river environment in recent years, because the channel bed is the foundation of the river eco-system. Barbs often perform poorly in strongly aggrading or degrading channels. According to Chow (1959), barbs are a trapezoidal shaped rock structure, which extends into the main flow of the river. In view of the fact that barbs tend to redirect water to the center of the stream, they encourage deposition between the barbs along the bank. When barbs designed effectively, as a result the structure induced a zone of subcritical flow at the upstream and along the channel bank. Water level increases in the zone of upstream of the barbs through the backwater as described by Chow (1959). The upstream progression of subcritical reaches flowing slowly, the water loses some of its capacity to carry load and sand or silt deposits on the river bed, building it up or aggrading it as well as sand bars are formed. In the near bank region its control erosion and ultimately leads to deposition of sediment along the protected bank line. Flow across the barb occurs cross-channel accelerations being forced around the emerging bars, however tend to decrease bottom shear stress higher up on the bars. As a result the bottom shear stresses decrease over the shoaling bar head and particles carried onto the bar head tend to be deposited (Lisle, 1991). Bars developed rapidly due to some causes such as initial bed condition, inlet flow and sand supply and propagate (increase in the bars wave length with time) new bars to downstream one by one just like a chain-reaction as stated Fujita and Muramotu (1985). Barbs influence near bank velocity and shear stress distribution through disruption of helicoidal currents and partial interception of crossstream flow. Flow across the barb occurs somewhat normal to the longitudinal axis of each structure and intersects the contraction-accelerated discharge at each barb end. The convergence of these flow components results in energy dissipation through turbulent flow mixing and forces the resultant vector flow direction away from the protected bank (NRCS, 2005).

The channel without any training structure, Mosselman (2009) studied by theoretical analysis and Crosato and Desta (2009) by their experimental observation, on current accepted view is that the bars formed as steady only if the width to depth ratio is at the value of resonance or if the bars are forced by steady local perturbation. The steady bars can also form by small-amplitude unsteadiness in the system. As the width to depth ratio increases, the strongly nonlinear competition between different modes not only affects significantly bars height and celerity but also enhance the selection of higher-mode configurations namely, central bar mode or multiple row bar mode (Colombini and Tubino, 1991). There are various researches that has been done for flows around hydraulic structures like spur dikes, barbs, groins, submerged vanes etc., the majority of the investigations have treated flow around these structures and prevent erosion of the bank. Kothyari and Raju (2001) reported that, the primary focus of previous investigations, such as, Gill (1972), Garde et al. (1961) and Ahmad (1953), on the study of scour at abutments and spur dikes was to predict an equilibrium or maximum design scour depth. Barbs induced energy re-distribution away from the outer bank towards the center of the channel results in scour near the ends of the barbs and realignment of the thalweg. Field observation and laboratory result showed by Johnson, et al. (2001), Matsuura and Townsend (2004), Kuhnle et. al. (2002) that, the scour depth occurs at the barb end and immediately downstream of the structure. Barbs are currently undergoing limited field test on selected bend of several shallow wide streams in Illions, USA (Matsuura and Townsend, 2004). Moreover, investigation and estimation of the depth of local 
scour and deposition around a structure, such as a barb, remains a perplex problem for hydraulic and restoration engineers. Most investigations have just reported measurements of the maximum depth of scour without giving any information about the geometry (i.e. shape) of the scour hole and how this geometry changes with time (Kuhnle et al., 2002). Furthermore, it is need to investigate the effects of barbs on bed configuration considering uniform flow condition. This paper reports two-dimensional numerical simulation to observe the influence of barb on channel bed evolution from pre-exist straight channel and after install stream barb with erodible bed among a relatively high width-to-depth ratio.

\section{Materials and Methods}

A $13.3 \mathrm{~m}$ long and $0.8 \mathrm{~m}$ wide grid channel generated by using iRIC-Nays2D, computational flow model, a multi-dimensional river flow and riverbed variation analysis solver package. Several numerical models have been developed to simulate the deformation of a relatively narrow, deep, straight channel with erodible, no cohesive banks in the laboratory (Shimizu 2002). The channel shape was considered as rectangular flat movable bed with simple cross section. The slope of the channel was used as 0.005, as the model is designed by subcritical flow. Grid cells were generated along the longitudinal and lateral direction of hundred and ten numbers, respectively. It was estimated that the change of width of the grid channel in the direction of flow is constant. To evaluate the barbs hydraulic performance in channel bed configuration, the model was run two settings: first, in the pre-existing condition (i.e. before constructing the barb) second, in the presence of the barb installed on sidewall of the channel. At first flow approached into the channel pre-existing condition and find the velocity vector, flow depth and the elevation of the bed topography, respectively. Before starting flow provided small perturbation value at 5 selected grid nodes that are persuade the bars formation. The elevation set as zero along the whole channel alternately around $2.5 \mathrm{~m}$ equal distance. The barb structure is installed as obstacle at one channel sidewall and it is $4.5 \mathrm{~m}$ apart from the upstream end of the channel as shown in Fig. $2 \mathbf{a}$ and $2 \mathbf{b}$. The length of the barb considered as $24 \mathrm{~cm}$, one-third of the cross-section top width at bank full stage and build as rectangular riprap shape. At the end of barb the nodes elevation also decreased for creates its sloping crest. According to NRCS (2005), each barb extends from the bank-line to the proposed thalweg location. Generally the length of the barb not exceed one-third of the cross-section top width at bank full stage, as Matsuura and Townsend (2004) observed in their study that, the overall length should not exceed about one quarter the channel-forming flow width. By decreasing the nodes elevation point at the barb end, the structure set as a sloping ridge from the bank to the main channel flow.

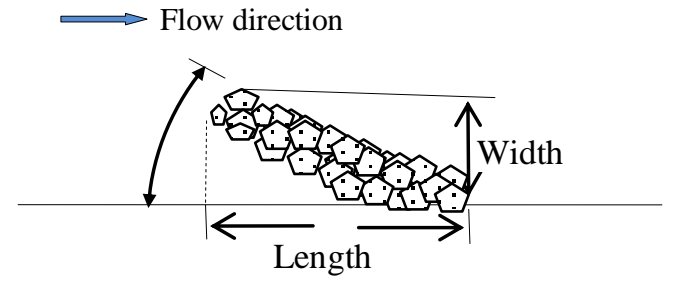

Fig. 2a. Sketch of the barb prototype

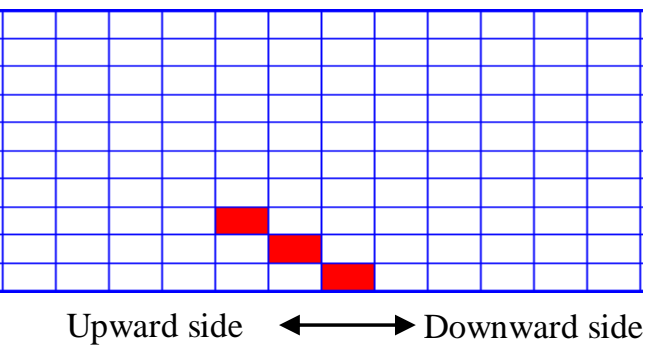

Fig. 2b. Riprap barb structure setting on grid channel bank sidewall 
The barb placed at an angle of $45^{\circ}$ with the upstream bank of the channel as NRCS (2005) state the horizontal angle between the tangent lines placed along the upstream bank and the centerline of the longitudinal axis of the barb has varied from $30^{\circ}$ to $60^{\circ}$. The generated grid channel was used to set the calculation condition and simulation. The Table 1 . below summarize the flow calculation condition for simulation. The symbol $\mathrm{L}$ represents as the total length, $B$ is the internal width and $S$ is the slope of the channel, D is the normal flow depth, Q is the discharge, $U$ is the velocity of the flow, $B / D$ is the width to average flow depth ratio, $C_{f}$ is the roughness coefficient correspond to $d_{50}$, where $d_{50}$ is the mean sediment diameter and Froude number, $F_{r}=\frac{U}{\sqrt{g D}}$, and $\mathrm{g}$ is gravity acceleration. The friction coefficient $C_{f}$ is found to be expressed as follow:

$$
C_{f}=\left[\frac{1}{K} \ln \frac{11 D}{2.5 d_{s}}\right]^{-2}
$$

The bottom share stress from the Reynolds equation, $\tau=\rho g D S$ and from the Keulegan relation for turbulent flow, the bed shear stress, $\tau=\rho C_{f} U^{2}$.

Where $\rho$ is the density of water. Considering unit

flow depth into the channel then, $U=Q / D$. Using from the relation $\tau=\rho g D S=\rho C_{f} U^{2}$ the discharge and velocity is calculated from the equation as follows:

$$
\frac{Q}{D}=\sqrt{\frac{g D S}{c_{f}}}
$$

Table. 1. Details flow calculation condition

\begin{tabular}{|c|c|c|c|c|c|c|c|c|c|}
\hline $\mathrm{L}$ & $\mathrm{B}$ & $\mathrm{S}$ & $\mathrm{B} / \mathrm{D}$ & $\mathrm{D}$ & $\mathrm{Q}$ & $\mathrm{U}$ & $\mathrm{C}_{\mathrm{f}}$ & $\mathrm{Fr}$ & $\mathrm{d}_{50}$ \\
\hline $\mathrm{m}$ & $\mathrm{m}$ & $\mathrm{m} / \mathrm{m}$ & - & $\mathrm{m}$ & $\mathrm{m}^{3} / \mathrm{s}$ & $\mathrm{m} / \mathrm{s}$ & - & - & $\mathrm{mm}$ \\
\hline 13.3 & 0.8 & 0.005 & 18 & 0.044 & 0.028 & 0.64 & 0.005423 & 0.977 & 0.77 \\
\hline
\end{tabular}

In the calculation condition used the professional solver type with bed deformation. The finite differential methods of advection term was used as CIP method. For calculation of numerical simulation the cyclic boundary condition was used with initial water surface as uniform flow. The upstream velocity and water surface at downstream was also considered as uniform flow. Constant discharge time series were used from the beginning up to 5 hours (Table 1). Output time interval was select as $10 \mathrm{sec}$. The calculation time step was set according to CourantFriedrichs-Lewy (CFL) condition as stated in equation (3). The CFL condition is necessary for convergence of flow while solving certain partial differential equations numerically by the method of finite differences (Courant et al. 1956).

$\frac{\Delta t}{\Delta x / u} \leq C \quad \Rightarrow \Delta t=C * \Delta x / u$

Where $\mathrm{C}$ is a dimensionless constant and it's vary from $0.1 \sim 0.3$. The maximum iteration times of water surface calculation was set as 20 . The diameter of the bed material was used as $0.77 \mathrm{~mm}$ and bed roughness calculated from the bed materials using equation (1).

\section{Results and Discussion}

The result of the flow fields and bed-topographies are presented in this section to understand the morph dynamics resulted from dealings of two settings: in before constructing the barb and in the presence of the barb. In order to compare these results of pre-existing condition and presence of barb there are three forms of result are considered in this numerical simulation. The difference between the results of two settings was considered to be the effects of barb on the channel bed configuration. The velocity profile was considered to recognize the flow pattern, bed elevation for identify the sediment deposition and flow depth to know the scour depth from both arrangements. Figures 3 to 9 comparatively illustrated the effects of barb on velocity vector, bed elevation, water flow depth.

\section{Velocity field}

The velocity vectors at water surface were obtained from simulation for pre-existing condition (without barb) and with single barb, respectively. Fig. 3 (a) and (b) shows the simulation result of velocity vector without barb structure after 1 hour and 5 hours, respectively. When the flow approaches into the channel without barb, the flow towards the channel and creates parabolic flow pattern that's influences to 
formation of double row bars. The flow pattern is not change into entire channel after long time simulation. Fig. 4 (a) and (b) shows the simulation effect of velocity vector at the water surface by installing single barb after 1 hour and 5 hours, respectively. In that case due to the flow separation at barb head return current developed at the upstream side induced zone of subcritical flow and along the stream bank.
Barb influenced the flow at downstream side and creates a mixing zone just behind the structure along the near bank line. The flow across the structure occurs contraction-accelerated discharge at the barb end. The convergence of these flow components result turbulent mixing around the barb head and vector flow directed towards the outer bank near water surface.
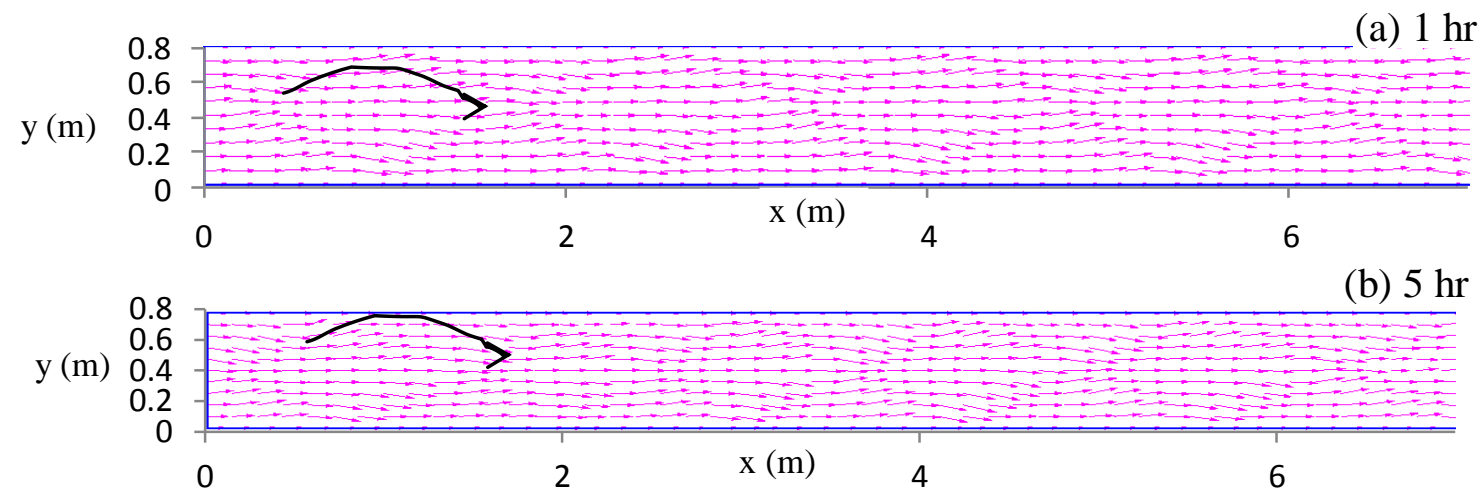

Fig. 3. Velocity field simulation result at water surface into the channel without barb (a) after 1 hour (b) after 5 hour.

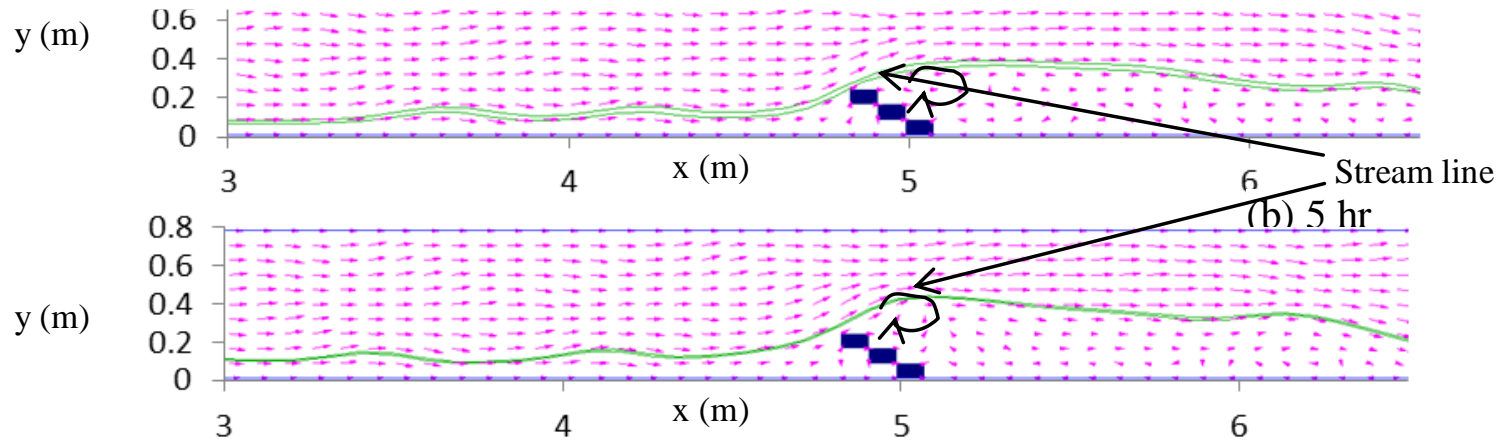

Fig. 4. Velocity field with a barb installed at one sidewall of the channel (a) after 1 hour simulation (b) after 5 hour simulation.

\section{Bed elevation around the structure}

The flow patterns with sediment transport were persuaded to build the scour-hole and deposition. In general the flow initiates and controls the scours and deposition. Fig. 5 shows the simulation result with the depositional contour lines of pre-existing channel after 1 hour and 5 hours, respectively. In pre-existing channel double row bars are formed due to flow and these formation of bars are becomes more perceptible after 5 hours simulation. Fig. 6 shows the simulation result with the depositional contour lines among single barb after 1 hour and 5 hours, respectively. Deposition occurred as sand bars along the bank-line at the upstream side of the structures. The formation of bars changing trend from double row to alternate due to long time simulation on upstream side of the barb field. Because of potential energy increased in the zone of upstream through backwaters effects. The upstream progression of subcritical reaches in the near bank region controls erosion and ultimately leads to deposition of sediments along the bank-line. In addition reduction of near bank velocity gradient through the subcritical backwater effect promotes sediment deposition upstream of the barb structure. At the downstream side of barb especially near the barb head scour occurs due to hydraulic jump and turbulence from flow mixing. The scour depth occurs at the barb end and immediately downstream of the structure because of energy re-distribution away from the outer bank towards the center of the channel results in scour near the ends of the barbs (Matsuura 
and Townsend (2004). This scour result is from contraction flow acceleration by local reduction of width to depth ratio. The remark was that sediment were scoured in the downward portion of the barb and deposited in the upward side of the barb. Fig. 7 represents the bed elevation of pre-exist channel and after barb installation at different times. This result shows clearly the applicability of barbs reduced the erosion around the structure and increases the pool habitat near the thalweg, which can be useful for natural rivers training work.
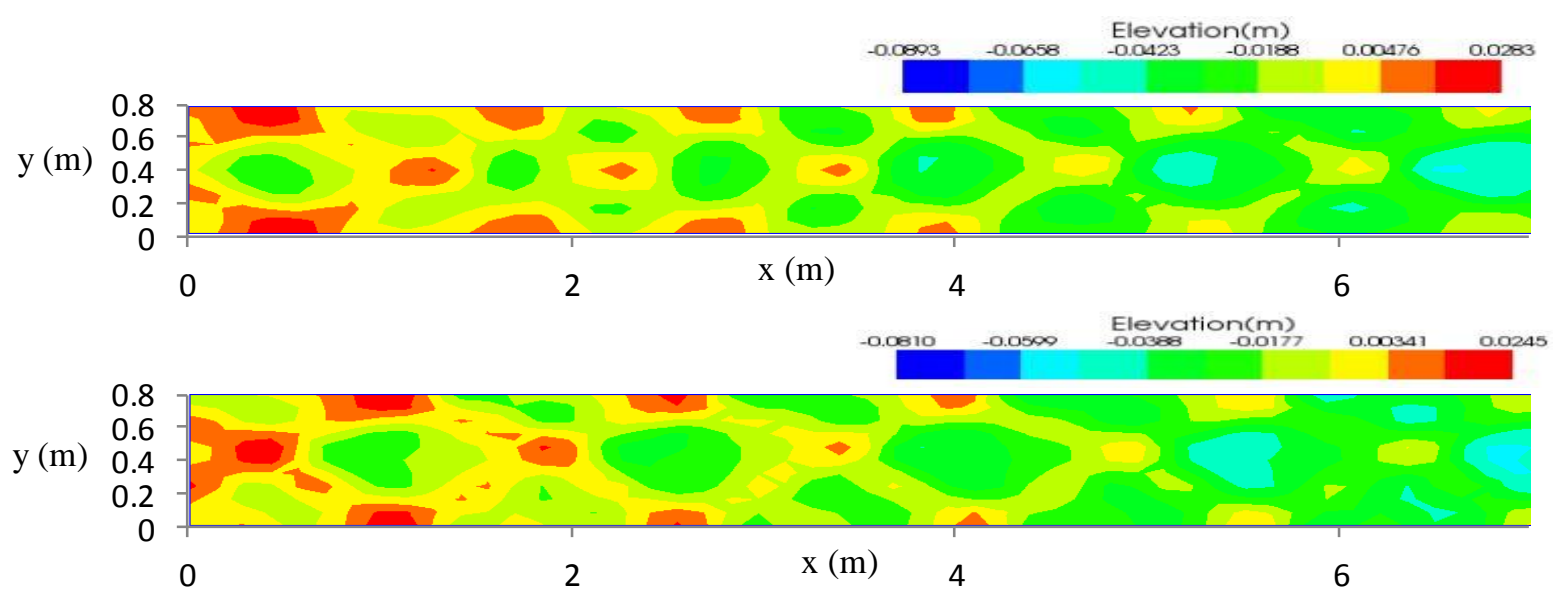

Fig. 5. Bed level contour result of the channel without any structure (top: after 1 hour simulation, bottom: after 5 hour simulation).

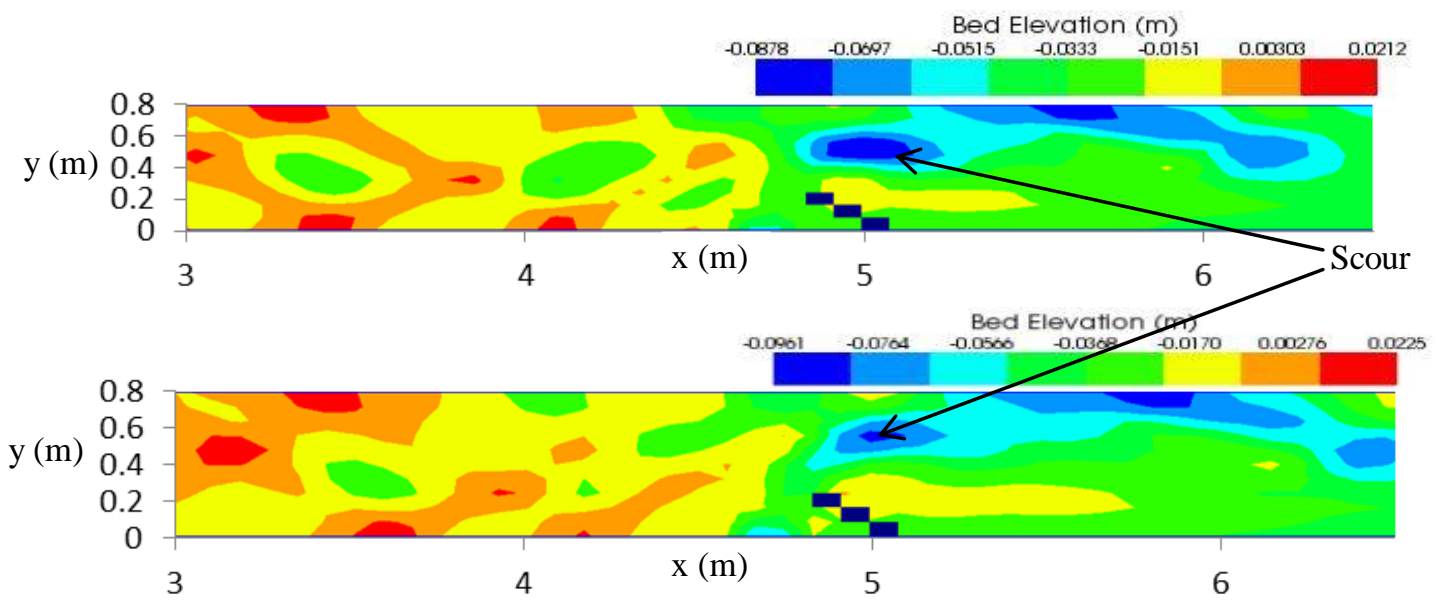

Fig. 6. Bed level contour result of the channel with a barb installed at one sidewall of the channel (top: after 1 hour simulation, bottom: after 5 hour simulation). 
(a)

(c)


(b)
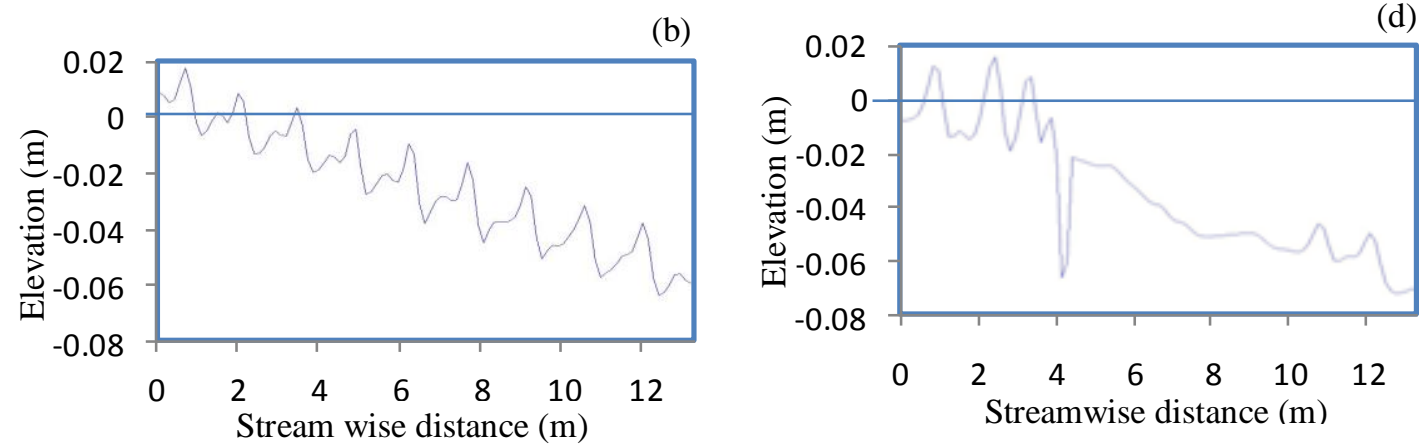

Fig. 7. Evolution of bed profile \& Comparison with pre-existing condition and after installed single barb at different times. (a) \& (b) represents the bed elevation of pre-existing channel after 1 and 5 hours, respectively. (c) \& (d) represents bed elevation with single barb after 1 and 5 hours, respectively.

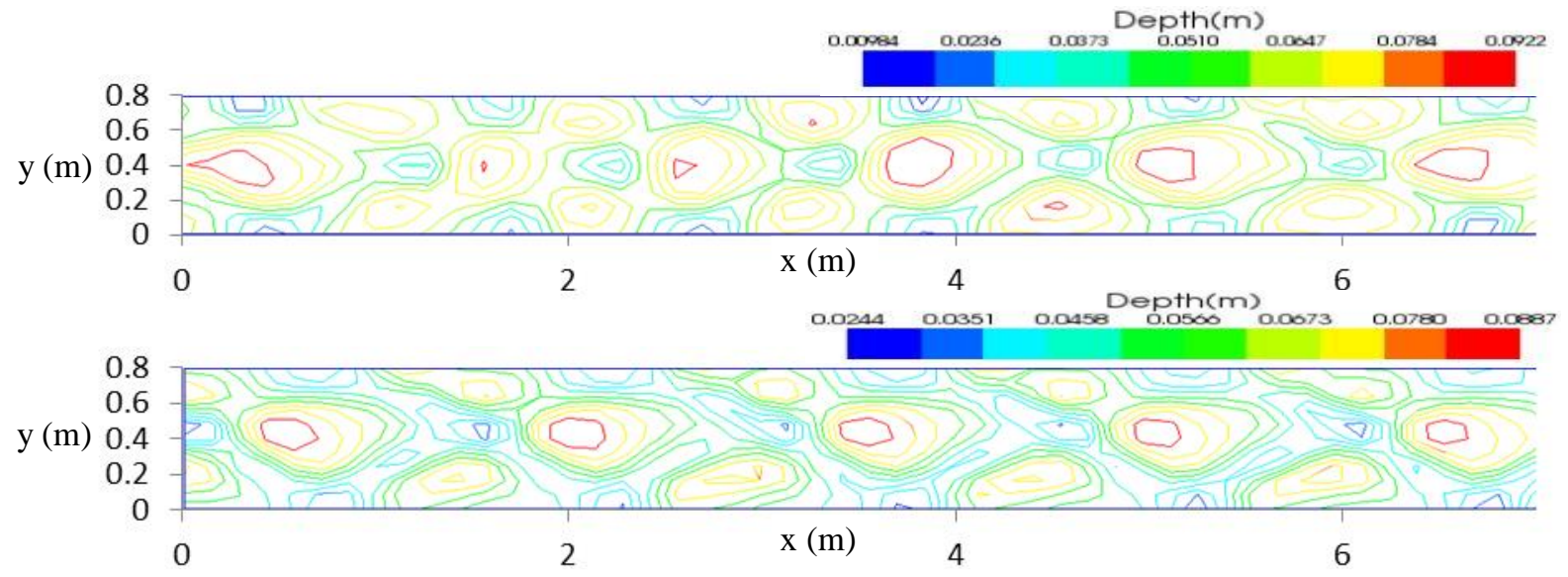

Fig. 8. Water depth contour result of the channel without barb structure (top: after 1 hour simulation, bottom: after 5 hour simulation). 



Fig. 9. Water depth contour result of the channel with a barb installed at one sidewall of the channel (top: after 1 hour simulation, bottom: after 5 hour simulation).

\section{Conclusion}

The study was conducted by two-dimensional numerical simulation to observe the effects of barb on bed configuration installed in channel sidewall. Information was provided regarding flow patterns and bed configuration (scour and deposition). A comparison was done between pre-exist straight channel and after installation of a stream barb with erodible bed among a relatively high width-to-depth ratio. Using nearly uniform sand under controlled steady flow conditions the bars are formed at the upstream portion of the channel. The flow towards the pre-exist channel creates parabolic flow pattern that's influences to formation of double row bars. In case of after barb installation, due to the flow separation at barb head, return current developed at the upstream side induced zone of subcritical flow along the stream bank. It influenced the flow at downstream side creates a mixing zone just behind the structure and along the near bank line. Potential energy increased in the zone of upstream through backwaters effects. The upstream progression of subcritical reaches in the near bank region control erosion and ultimately leads to deposition of sediments along the bank-line. At the downstream side of barb especially near the barb head scour occurs due to hydraulic jump and turbulence from flow mixing. In pre-existing channel flow depth with scour hole varied from $1 \mathrm{~cm}$ to $9 \mathrm{~cm}$ and marked a little variation of depth in entire simulation time. As expected flow depth was present around the end of the barb and the water depth including scour whole varied between $2 \mathrm{~cm}$ to $12 \mathrm{~cm}$. In conclusion, the simulation results showed that the installed barb successfully reduced the flow velocity along the bank and increased the turbulence velocity at the end of the barb structure, thereby successfully increasing the conveyance in the center of the channel. This means the barb would be able to reduce the erosion by forming bars along the near bank of the channel. However, experimental study need to verify simulation result and required to test their general acceptability.

\section{References}

Ahmad, M. 1953. Experiments on design and behavior of spur-dikes. Proc., Minnesota International Hydraulic Convention, Minneapolis, Mn (Sept. 1953), pp. 145-159.

Breusers, H. N. C. and Raudkivi, A. J. 1991. Scouring. Hydraulic structures design manual, No. 2, Balkema, Rotterdam, The Netherlands, pp.146.

Chow, V. T. 1959. Open Channel Hydraulics, McGraw Hill, New York.

Colombini, M. and Tubino, M. 1991. Finiteamplitude free bars: A fully nonlinear spectral solution, in Sand Transport in Rivers, Estuaries and the Sea, edited by R. Soulsby and R. Bettes, A. A. Balkema, Brookfield, Vt. pp. 163-169.

Courant, R.; Friedrichs, K.; Lewy, H. 1956. On the Partial Difference Equations of Mathematical Physics, Courant Institute of Mathematical Sciences, New York University, New York. 
Crosato, A. and Desta, F. B. 2009. Intrinsic steady alternate bars in alluvial channels. Part 1: experimental observation and numerical tests. River, Coastal and Estuarine Morphodynamics: (RCEM). Santa Fe, Argentina. Vol.2, pp.759-765.

Davinroy, R. D. 1990. Bendway Weir Concept in the Mississippi River, Proceedings, International Association of Navigation Congresses, Secille, Spain, pp.115-123.

Davinroy, R. D. 1994. The Bendway Weirs, A New Structural Solution to Navigation Problems Experienced on the Mississippi River, International Association of Navigation Congresses, Bulletin 69, Osaka, Japan, pp.519.

Fox, J. F.; Papanicolaou, A. N. and Kjos, L. 2002. An Environmentally Friendly Barb design for Washington State, Research and Extension Regional Water Quality Conference, February 20- 21, Vancouver, WA.

Fujita, Y. and Muramoto, Y. 1985. Studies on the Process of development of Alternate Bars. Bulletin Disaster Prevention Research Inst. Kyoto Univ. Vol., 35(3) No. 314, pp.55-86.

Garde, R. J.; Subramanya, K. and Nambudripad, K. D. 1961. Study of scour around spur-dikes. J. Hydraul. Div., ASCE, 87 (HY6), pp. 23-37.

Ghodsian, M. and Tehrani, S. M. H. 2001. Scour around groins, International Journal of Sediment Research, 16(1): 60-68.

Gill, M. A. 1972. Erosion of Sand Bed Around Spur Dikes, J. Hydraul. Div., Proc. ASCE, Vol. 98, No. HY9, pp.1587-1602.

Hasen, E. M. and Winter, E. R. 1996. Abstract 0027: design abstract for barb. Northwest Region Hydraulic Sectin (Draft).

Johnson, P. A.; Hey, R. D.; Tessier, M. and Rosgen, D. L. 2001. Use of vanes for control of scour at vertical wall abutments, J. Hydr. Engrg., ASCE, 127(9): 772-778.

Kothyari, U. C. and Ranga Raju, K. G. 2001. Scour around spur dikes and bridge abutments. Journal of Hydraulic Research, 39(4): 367374.

Kuhnle, R. A.; Alonso, C. A. and Shields Jr., F. D. 2002. Local scour associated with angled spur dikes, J. Hydr. Engrg., 128(129): 10871093.
Lisle, T. E. 1991. Formation of stationary alternate bars in a steep channel with mixed-size sediment: A flume experiment. Earth Surface Processes and Landforms. Vol. 16. pp 463-469.

Lloyd, P. M. and Stansby, P. K. 1997. Shallow-water flow around model conical islands of small side slope. II: submerged. J. Hyd. Engr., ASCE, 123(12): 1068-1077.

Matsuura, T. and Townsend, R. D. 2004. A Laboratory study of barbs installations in narrow-channel bends; phase 2. Advances in Hydro-Science and -Engineering, Volume VI: Proceedings of Abstracts and Papers (on CD-ROM) of the 6th International Conference on Hydro-Science and Engineering, Brisbane, Australia.

Mosselman, E. 2009. Intrinsic steady alternate bars in alluvial channels. Theoretical analysis. River, Coastal and Estuarine Morphodynamics: (RCEM). Vionnet et. Al. (eds). Tailor \& Francis Group, London. pp. 767-772.

NRCS, 2005. Technical Note 23, Design of Stream Barbs (Version 2.0). U.S. Department of Agriculture, Portland, Oregon. Oregon Bulletin No. OR210-2005-2, pp.1-25.

Papanicolaou, A. N. T.; Kjos, J. L. and Fox J. F. 2004. Investigation of Flow and Local Scour Characteristics around a Partially Submerged Permeable WSDOT Barb. Final report, No. WA-RD 581.1. Washington State Transportation Center (TRAC).

Pizzuto, J. E. 1990. Numerical simulation of gravel river widening. Water Resour. Res., 26(9): 1971-1980.

Schiechtl, H. M. and R. Stern. 1996. Water Bioengineering Techniques for Watercourse, Bank and Shoreline protection. Trans by L. Jaklitsch. Blackwell Scientific. Oxford, UK. P. 185.

Shimizu, Y. 2002. A method for simultaneous computation of bed and bank deformation of a river. River Flow 2002, Int. Conf. on Fluvial Hydraulics, Louvian-la-Neuve, Belgium, pp.793-801.

USDA, 2001. Design of Stream Barbs, Technical Notes, Engineering No. 12, Version 1.4, US Department of Agriculture, Natural Resources Conservation Service, Boise, ID 